\title{
Abordagem morfológica e molecular da diversidade da família Ganodermataceae no estado da Bahia.
}

\section{JEFFERSON LIMA LOPES ${ }^{1}$; Diogo Henrique Costa de Rezende ${ }^{2}$; Raquel Guimarães Benevides ${ }^{3}$;}

1. 1. Bolsista Fapesb, Graduando em Ciências Biológicas, Universidade Estadual de Feira de Santana, e-mail: jeff.16.j11@gmail.com

2. Doutorando, DCBIO, Universidade Estadual de Feira de Santana, e-mail: diogo_agrolab@ hormail.com

3. Orientador, DCBIO, Universidade Estadual de Feira de Santana, e-mail: raquelgb@gmail.com

PALAVRAS-CHAVE: Basidiomycota, Amplificação, Microrganismos.

\section{INTRODUÇÃO}

Ganodermataceae Donk (Polyporales Gäum, Agaricomycetes Doweld) é uma família em que estão contidos fungos macroscópicos do filo Basidiomycota R.T. Moore, que se caracterizam principalmente por apresentar basidiomas pileados, sésseis a estipitados, sistema hifal di-trimítico com presença de hifas esqueletais arboriformes e pela presença de basidiósporos com parede dupla, onde a interna apresenta ornamentação, sendo esta, uma característica exclusiva do táxon (RYVARDEN, 2004).

Muitas espécies da família causam podridão branca na madeira, sendo que depois de sofrer a ação desses fungos o substrato fica com aspecto esponjoso, fibroso ou laminado e de cor esbranquiçada. Além de saprófitas, a família apresenta espécies que são parasitas obrigatórias e facultativas (FURTADO 1981, TURNER 1981, RYVARDEN 2004, GLEN et al. 2009, KINGE \& AM 2011, NAHER et al. 2013).

Tendo em vista que os dados comprovam que somente características morfológicas não são suficientes para delimitação de espécies de Ganodermataceae, análises a partir do DNA Barcode são uma ferramenta interessante para a abordagem da diversidade da família. O método consiste na utilização de um pequeno segmento padronizado de DNA (código de barras) que seja suficientemente variável a nível específico, mas pouco variável ao nível infraespecífico, baseado na premissa de que a variação genética entre as espécies analisadas excede a variação existente dentro destas mesmas espécies para o segmento de DNA selecionado (HERBERT et al., 2003).

O objetivo deste trabalho, portanto, foi realizar a preparação de espécimes dessa família para estudos moleculares, que servirá de aparato para posterior análise e interpretação da diversidade da família Ganodermataceae na Bahia a partir de análises moleculares (DNA barcoding).

\section{MATERIAL E MÉTODOS OU METODOLOGIA (ou equivalente)}

Estudos Moleculares 
Amostras de DNA previamente extraídas de basidiomas da família Ganodermataceae coletados de diversas localidades no Brasil foram cedidas pelo grupo de pesquisa.

Amplificação do DNA (PCR)

Para realizar a PCR foi preciso realizar a diluição do produto de extração de 1 pra 10. Para solução de PCR preparou-se em um tubo de $1,5 \mathrm{ml}$ um mix com reagentes para posteriormente adicionar a amostra de DNA já diluída-.;

No mix de PCR foram adicionados 13,-45 $\mu \mathrm{L}$ de $\mathrm{H}_{2} \mathrm{O}$ ultrapura, 2,,5 $\mu \mathrm{L}$ de tampão de PCR segundo o fabricante, $0,-5 \mu \mathrm{L}$ de dNTP, $0,75 \mu \mathrm{L} \mathrm{MgCl}_{2}$ (-Cloreto de Magnésio), 1,-25 $\mu \mathrm{L}$-dos Primers F e R (IDT), e 0,-3 $\mu \mathrm{L}$ da Taq Polimerase (-KAPPA BIOSYSTEMS). O mix foi preparado em um recipiente com gelo para manter baixa a temperatura dos reagentes até o uso. Foram utilizados os seguintes pares de primers para amplificar as regiões LSU, ITS, RPB1 e TEF1, respectivamente: LR0R/LR7 (Binder et al., 2005; Justo \& Hibbett, 2011-); ITS 6R/ITS8F (Dentinger et al. 2010); RPB1-Af/RPB1-Cr (Matheny \& al.,2002; Justo \& Hibbett, 2011) e TEF1 EF1-983F/EF1-2012R (Rehner \& Buckley, 2005; Justo \& Hibbett, 2011).

Após o preparo do mix adicionou-se a amostra contendo o DNA diluído e em seguida agitado em vortex para depois ser inseridas as amostras em termociclador e neste selecionado o programa para amplificação de acordo com a região que será feita a amplificação (Tabela 1).

Tabela 1. Protocolo de ciclagem da Amplificação (PCR)

\begin{tabular}{l|c|c|c}
\hline \multicolumn{1}{c|}{ Etapas } & Temperatura & Duração & Ciclos \\
\hline Desnaturação Inicial & $94^{\circ}-95^{\circ} \mathrm{C}$ & $4-5$ min. & 1 \\
\hline Desnaturação & $94^{\circ}-95^{\circ} \mathrm{C}$ & $1 \mathrm{~min}$. & 35 \\
\hline Anelamento & $50^{\circ}-57^{\circ} \mathrm{C}$ & $1 \mathrm{~min}$. & 35 \\
\hline Extensão & $72^{\circ} \mathrm{C}$ & $1 \mathrm{~min}$. & 35 \\
\hline
\end{tabular}

Análise da PCR por eletroforese em gel de agarose

Para a eletroforese utilizou-se gel de agarose a 1,2\% em $120 \mathrm{~mL}$ de tampão TAE. Após 30 minutos a $100 \mathrm{v}$ e $90 \mathrm{~mA}$ de corrida eletroforética, o gel foi analisado por visualização em fotografia digital (KODAK EDAS 290 ${ }^{\circledR}$ ). A partir da eletroforese foi possível verificar se houve amplificação do DNA das amostras nas regiões quais foram amplificadas.

\section{RESULTADOS E/OU DISCUSSÃO (ou Análise e discussão dos resultados)}

Foram amplificados o material genético para regiões ITS, LSU-, RPB e TEF, para os fungos coletados na cidade de Camacan-Ba_(Tabela 2)-, Serra Grande -Ba (Tabela 3), Chapada dos Guimarães- MT (Tabela 4), Novo Airão- AM (Tabela 5) e Belterra- PA (Tabela 6) que apresentaram qualidade na extração de DNA. 
No geral, das 42 amostras que foram feitas o procedimento de amplificação para as regiões ITS, LSU, RPB e TEF, apenas 9,52\% não amplificaram em nenhuma das regiões.

Para os fungos coletados na cidade de Camacan-Ba (Tabela 2), dos 10 coletados e submetidos à amplificação, apenas 3 não amplificaram nas seguintes regiões: DHCR 502, na região LSU, -DHCR 505 na região ITS, e DHCR 509 nas regiões LSU e RPB.

Tabela 2. Tabela para regiões amplificadas dos fungos coletados em Camacan-Ba

\begin{tabular}{|c|c|c|c|c|c|}
\hline Gênero & $\mathbf{N}^{\circ}$ de Voucher & ITS & LSU & RPB & TEF \\
\hline Amauroderma & DHCR496 & $\mathrm{X}$ & $\mathrm{X}$ & $\mathrm{X}$ & $\mathrm{X}$ \\
\hline Amauroderma & DHCR499 & $X$ & $\mathrm{X}$ & $\mathrm{X}$ & $\mathrm{X}$ \\
\hline Amauroderma & DHCR500 & $\mathrm{X}$ & $\mathrm{X}$ & $\mathrm{X}$ & $\mathrm{X}$ \\
\hline Amauroderma & DHCR501 & $\mathrm{X}$ & $\mathrm{X}$ & $X$ & $\mathrm{X}$ \\
\hline Amauroderma & DHCR502 & $\mathrm{X}$ & $-*$ & $X$ & $X$ \\
\hline Amauroderma & DHCR503 & $\mathrm{X}$ & $\mathrm{X}$ & $X$ & $\mathrm{X}$ \\
\hline Amauroderma & DHCR504 & $\mathrm{X}$ & $\mathrm{X}$ & $\mathrm{X}$ & $\mathrm{X}$ \\
\hline Amauroderma & DHCR505 & - & $\mathrm{X}$ & $\mathrm{X}$ & $X$ \\
\hline Ganoderma & DHCR509 & $X$ & - & - & $\mathrm{X}$ \\
\hline Amauroderma & DHCR512 & $X$ & $\mathrm{X}$ & $\mathrm{X}$ & $\mathrm{X}$ \\
\hline
\end{tabular}

*- Amostra não apresentou produto de amplificação

Para os fungos coletados na cidade de Serra Grande-Ba (Tabela 3), dos 03 coletados e feito a amplificação, 2 não amplificaram nas seguintes regiões: DHCR 529, nas regiões LSU,RPB e TEF, DHCR 535 na região TEF.

Tabela 3. Tabela para regiões amplificadas dos fungos coletados em Serra Grande-Ba.

\begin{tabular}{llllll}
\hline Gênero & $\begin{array}{l}\mathbf{N}^{\circ} \text { de } \\
\text { Voucher }\end{array}$ & ITS & LSU & RPB & TEF \\
\hline Phellinus & DHCR529 & X & $-*$ & - & - \\
Amauroderma & DHCR534 & X & X & X & X \\
Amauroderma & DHCR535 & X & X & X & - \\
\hline
\end{tabular}

*- Amostra não apresentou produto de amplificação

Para os fungos coletados na cidade de Chapada dos Guimarães-MT (Tabela 4), dos 26 fungos coletados e feito as análises, 19,23\% -não amplificaram na região ITS, $30,77 \%$ não amplificaram na região LSU, 42,31 \% não amplificaram na região RPB, e 65,38\% não amplificaram na região TEF.

Tabela 4. Tabela para regiões amplificadas dos fungos coletados na cidade Chapada dos Guimarães-MT.

\begin{tabular}{llllll}
\hline Gênero & $\begin{array}{l}\mathbf{N}^{\circ} \text { de } \\
\text { Voucher }\end{array}$ & ITS & LSU & RPB & TEF \\
\hline Amauroderma & DHCR538 & X & X & X & $-*$ \\
Amauroderma & DHCR539 & X & - & - & - \\
Amauroderma & DHCR540 & X & X & X & X \\
Amauroderma & DHCR541 & - & - & - & - \\
Amauroderma & DHCR542 & X & X & - & - \\
\hline
\end{tabular}




\begin{tabular}{|c|c|c|c|c|c|}
\hline Amauroderma & DHCR543 & - & - & - & - \\
\hline Amauroderma & DHCR544 & $\mathrm{X}$ & - & $X$ & X \\
\hline Amauroderma & DHCR545 & $X$ & $X$ & - & - \\
\hline Amauroderma & DHCR546 & $\mathrm{X}$ & $X$ & $\mathrm{X}$ & $X$ \\
\hline Amauroderma & DHCR547 & $X$ & $X$ & $X$ & $\mathrm{X}$ \\
\hline Amauroderma & DHCR548 & $\mathrm{X}$ & $X$ & - & - \\
\hline Amauroderma & DHCR549 & - & - & - & - \\
\hline Amauroderma & DHCR550 & $\mathrm{X}$ & $X$ & $\mathrm{X}$ & $X$ \\
\hline Amauroderma & DHCR551 & $\mathrm{X}$ & $X$ & $\mathrm{X}$ & - \\
\hline Amauroderma & DHCR552 & - & - & - & - \\
\hline Amauroderma & DHCR553 & $\mathrm{X}$ & $X$ & $\mathrm{X}$ & - \\
\hline Amauroderma & DHCR554 & $\mathrm{X}$ & $X$ & $X$ & - \\
\hline Amauroderma & DHCR555 & $\mathrm{X}$ & $X$ & - & - \\
\hline Amauroderma & DHCR556 & $\mathrm{X}$ & $X$ & $\mathrm{X}$ & $\mathrm{X}$ \\
\hline Amauroderma & DHCR557 & - & - & - & - \\
\hline Amauroderma & DHCR558 & $\mathrm{X}$ & - & $\mathrm{X}$ & - \\
\hline Ganoderma & DHCR559 & $\mathrm{X}$ & $\mathrm{X}$ & $X$ & $\mathrm{X}$ \\
\hline Amauroderma & DHCR560 & $X$ & $X$ & $\mathrm{X}$ & $X$ \\
\hline Amauroderma & DHCR561 & $\mathrm{X}$ & $X$ & $X$ & - \\
\hline Amauroderma & DHCR562 & $\mathrm{X}$ & $X$ & - & - \\
\hline
\end{tabular}

*- Amostra não apresentou produto de amplificação

Para os fungos coletados na cidade de Novo Airão-AM (Tabela 5), dos 2 coletados e submetidos a amplificação, estes ambos não amplificaram nas seguintes regiões: RPB e TEF.

Tabela 5. Tabela para regiões amplificadas dos fungos coletados em Novo Airão- AM.

\begin{tabular}{llllll}
\hline Gênero & $\mathbf{N}^{\circ}$ de Voucher & ITS & LSU & RPB & TEF \\
\hline Ganoderma & DHCR359 & X & X & $-*$ & - \\
Ganoderma & DHCR379 & X & X & - & - \\
\hline
\end{tabular}

*- Amostra não apresentou produto de amplificação

Para o fungo coletado na cidade de Belterra- PA (Tabela 6), este não amplificou nas regiões ITS e TEF.

Tabela 6. Tabela para regiões amplificadas dos fungos coletado em Belterra- PA.

\begin{tabular}{llllll}
\hline Gênero & $\mathbf{N}^{\circ}$ de Voucher & ITS & LSU & RPB & TEF \\
\hline Ganoderma & DHCR194 & $-*$ & $X$ & $X$ & - \\
\hline
\end{tabular}

*- Amostra não apresentou produto de amplificação

Pelo que se pode perceber, o uso da região ITS para amplificação é bastante satisfatório: nos resultados de amplificação mostrados acima, poucos foram os fungos que não amplificaram nessa região. As regiões ITS dispõem de características interessantes para a identificação dos fungos em nível molecular. Uma delas é que, nos fungos, esta região, que compreende entre 600 e 800 pares de bases, é amplificada, 
utilizando os primers universais, os quais são complementares às sequências altamente conservadas dos genes que codificam o rRNA. Outra característica importante deve-se à natureza repetitiva do rDNA, que torna esta região fácil de amplificar a partir de amostras pequenas, diluídas e altamente degradadas-,_entretanto, o uso de outras regiões como RPB , LSU E TEF fazem- se necessárias justamente por ser locais mais variáveis (Gardes \& Bruns, 1993).

Em relação às regiões RPB, LSU e TEF, para todas houveram amostras que apresentaram produto de amplificação esperado que compreende entre 600 e 800 pares de bases. O uso destas regiões conferem muitas vantagens, pois funcionam com fragmentos pequenos de material biológico, possibilitando a identificação facilitada de espécies associadas à preservação do espécime, que é crítico para preservação de acervos de Museus e Coleções institucionalizadas e também aceleram a identificação de organismos conhecidos e também facilita o reconhecimento rápido de novas espécies (Ali et al., 2014).

\section{CONSIDERAÇÕES FINAIS (ou Conclusão)}

De acordo com a análise das amostras amplificadas houve um grande sucesso no uso da região ITS, pois $83,33 \%$ do total das amostras obtiveram êxito na amplificação, um êxito também a região LSU que obteve-se $73,8 \%$ do total das amostras ,na região RPB obteve-se êxito na amplificação do total das amostras de 64,28\% enquanto que a região TEF obteve-se do total de 47,61\%.

Já que houve amplificação em todas as regiões que foram utilizadas, existem então condições para passar às próximas etapas que serão utilizadas para determinação / identificação dos organismos da família.

\section{REFERÊNCIAS}

ALI, M.A. ; GYULAI, G.; HIDVE’'- GI, N. ; KERTI, B.; AL -HEMAID , F.M.A.; PANDEY, A.K.; LEE, J. The changing epitome of species identification -DNA barcoding. Saudi Journal of Biological Sciences. 2014 Jul; 21(3):204-31.

BINDER, M.; HIBBETT, D. S.; LARSSON, K. H.; LARSSON, E.; LANGER, E. 2005. The phylogenetic distribution of resupinate forms in the homobasidiomycetes. Syst. Biodivers., 3: 113-157.

DENTINGER, B. T. M.; MARGARITESCU, S.; MONCALVO, J. M. 2010. Rapid and reliable highthroughput methods of DNA extraction for use in barcoding and molecular systematics of mushrooms. Molecular Ecology Resources, 10: 628-633.

FURTADO, J.S. 1981. Taxonomy of Amauroderma (Basidiomycetes, Polyporaceae). Memoirs of the New York Botanical Garden 34: 1-109

Gardes, M.; Bruns T.D. ITS primers with enhanced specificity for basidiomycetes - Application to the identification ofmycorrhizae and rust. Mol. Ecol., v.2, p.113- 118, 1993.

Australasian Plant Pathology, 38: 345-356.

HERBERT, P.D.N.; CYWINSKA, A.; BALL, S.L.; DEWARD, J.R. 2003. Biological identifications through DNA barcodes. Proc Biol Sci. 270(1512): 313-321,

JUSTO, A.; HIBBETT, D. S. 2011. Phylogenetic classification of Trametes (Basidiomycota, Polyporales) based on a five-marker dataset. Taxon, 60 (6): 1567-1583.

MATHENY, P. B.; LIU, Y. J.; AMMIRATI, J. F.; HALL, B. D. 2002. Using RPB1 sequences to improve phylogenetic inference among mushrooms (Inocybe, Agaricales). Amer. J. Bot., 89: 688-698.

KINGE, T. R.; MIH, A. M. 2011. Ganoderma ryvardense sp. nov. associated with basal stem rot (BSR) disease of oil palm in Cameroon. Mycosphere, 2(2), 179-188.

NAHER, L.; YUSUF, U. K.; ISMAIL, A.; TAN, S. G.; MONAL, M. M. A. 2013. Ecological status of Ganoderma and basal stem rot disease of oil palms (Elaeis guineensis Jacq.). AJCS 7, 1723-1727.

REHNER, S. A.; BUCKLEY, E. 2005. A Beauveria phylogeny inferred from nuclear ITS and EF1-a sequences: Evidence for cryptic diversification and links to Cordyceps teleomorphs. Mycologia, 97: 8498.

RYVARDEN L. 2004. Neotropical Polypores: Part 1. Introduction, Ganodermataceae \& Hymenochataceae. Fungiflora, Oslo.

| TURNER, P. D. 1981. Oil Palm Diseases and Disorders. Kuala Lumpur, Oxford Uni-versity Press, 281 pp. 